E-JURNAL EKONOMI DAN BISNIS UNIVERSITAS UDAYANA
Available online at https://ojs.unud.ac.id/index.php/EEB/index
Vol. 10 No. 04, April 2021, pages: 231-240
e-ISSN: 2337-3067

\title{
DETERMINAN PENGANGGURAN ANTAR KABUPATEN/KOTA DI JAWA BARAT
}

\author{
Adhitya Wardhana ${ }^{1}$, Bayu Kharisma ${ }^{2}$, Syafira Nur Lathifah ${ }^{3}$
}

\begin{tabular}{l}
\hline \multicolumn{1}{c}{ Article history: } \\
\hline \\
Submitted: 18 Januari 2021 \\
Revised: 28 Februari 2021 \\
Accepted: 3 Maret 2021 \\
\end{tabular}

\section{Keywords:}

Unemployment;

Mean of years schooling;

Poverty;

\section{Kata Kunci:}

Pengangguran;

Fixed effect;

Rata-rata lama sekolah;

Kemiskinan;

\section{Koresponding:}

Departemen Ilmu Ekonomi

Universitas Padjadjaran

Jawa Barat, Bandung

Email:

adhitya.wardhana@fe.unpad.ac.id
Abstract

This study aims to analyze the determinant of unemployment between districts / cities in West Java during the period 2011-2017. The research method used is data panel regression through fixed effect model. The results showed that the mean of year schooling and economic output were negative, while poverty and population had a positive relationship to unemployment. Aspects of education have an influence in lowering unemployment. Therefore, the need to increase the mandatory nine-year study target as an effort to improve the quality of human resources, especially for regions that have not reached the target. Furthermore, the policy of accelerating the economy by increasing its economic output and maintaining the population level in order to strike a balance in employment and unemployment so as not to continue to increase.

\section{Abstrak}

Penelitian ini bertujuan untuk menganalisa determinan pengangguran antar Kabupaten/Kota di Jawa Barat selama periode tahun 2011-2017. Metode penelitian yang digunakan adalah regresi panel data melalui model fixed effect. Hasil penelitian ini menunjukkan bahwa rata lama sekolah dan output ekonomi berhubungan negatif, sedangkan kemiskinan dan populasi memiliki hubungan yang positif terhadap pengangguran. Aspek pendidikan memiliki pengaruh dalam menurunkan pengangguran. Oleh sebab itu, perlunya peningkatan target wajib belajar sembilan tahun sebagai upaya peningkatan kualitas SDM, terutama bagi daerah yang belum mencapai target. Selanjutnya, kebijakan percepatan ekonomi dengan meningkatkan output perekonomiannya dan menjaga tingkat populasi agar terjadi keseimbangan di lapangan kerja dan angka pengangguran agar tidak terus meningkat.

Departemen Ilmu Ekonomi, Universitas Padjadjaran, Jawa Barat, Bandung ${ }^{2,3}$

Email: adhitya.wardhana@fe.unpad.ac.id ${ }^{2,3}$ 


\section{PENDAHULUAN}

Pengangguran merupakan permasalahan besar dalam makroekonomi suatu negara, dimana adanya peningkatan pengangguran dapat menyebabkan penurunan standar kehidupan dan kehilangan pekerjaan. Selain itu, jika kondisi tersebut tidak diatas maka akan menyebabkan masalah sosial ekonomi di negara tersebut. (Mankiw, 2006). Selain itu, pengangguran merupakan indikator angkatan kerja penting yaitu penduduk yang tidak mencari pekerjaan karena sudah diterima bekerja namun belum mulai bekerja, sedang mempersiapkan sebuah usaha yang baru dan penduduk yang tidak bekerja tetapi sedang berusaha untuk mencari pekerjaan (Badan Pusat Statistik, 2019).

Pengangguran merupakan salah satu masalah yang dapat terjadi di setiap daerah, bahkan negara maju sekalipun. Selain itu, dapat memperburuk stabilitas ekonomi suatu negara, termasuk terjadi di negara berkembang, salah satunya adalah Indonesia. Tingkat pengangguran yang terjadi di Indonesia tergolong tinggi, dimana pada tahun 2017 sebesar 5,5\% (Indonesia-investments, 2017). Kondisi tersebut menunjukkan bahwa angka pengangguran di Indonesia masih jauh lebih tinggi dibandingkan negara maju seperti Jepang yang hanya 2,8\%. Kondisi ini dapat terjadi antara lain karena adanya ketidaksesuaian antara pekerjaan dan pendidikan serta kemampuannya (Raharja \& Manurung dalam Hindun, 2019).

Provinsi Jawa Barat menjadi salah satu provinsi yang memiliki perekonomian maju tetapi penganggurannya sudah melebihi tingkat pengangguran Indonesia. Tingginya pengangguran di Provinsi Jawa Barat dibandingkan nasional karena adanya kualitas SDM yang jauh dari standar dan sempitnya lapangan kerja secara tidak langsung akan memperbesar pengangguran. Oleh karena itu, masyarakat yang tinggal di Jawa Barat agar tidak kehilangan pekerjaan perlu meningkatkan keahlian dan pendidikan yang dapat diterapkan dalam lingkup perkerjaan.

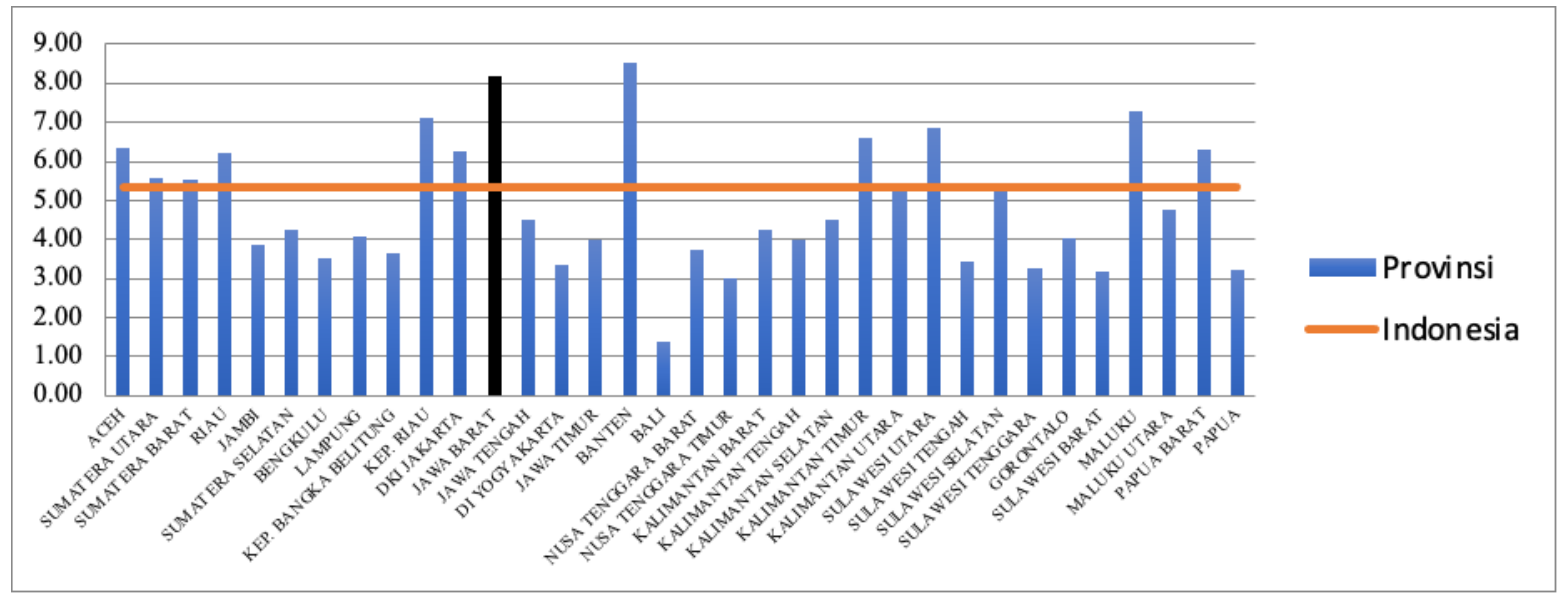

Sumber : BPS Indonesia (2018)

\section{Gambar 1.}

Tingkat Pengangguran Terbuka Provinsi di Indonesia Tahun 2018 (dalam persen)

Beberapa provinsi di Indonesia melebihi tingkat pengangguran di Indonesia, dimana salah satu provinsi yang melebihi tingkat penganguran Indonesia yaitu Provinsi Jawa Barat. Pada dasarnya, perkembangan pengangguran di Jawa Barat tidak terlepas dari lapangan pekerjaan berkurang akibat upah minimum yang mengalami peningkatan. Selain itu, berkurangnya jumlah perusahaan maupun pabrik yang beralih ke provinsi lain karena upah minimum lebih rendah mengakibatkan tingginya angka pengangguran di Provinsi Jawa Barat. Selanjutnya, besaran tingkat pengangguran terbuka terdapat di beberapa daerah Jawa Barat yang dapat dilihat pada Gambar 2 berikut. 


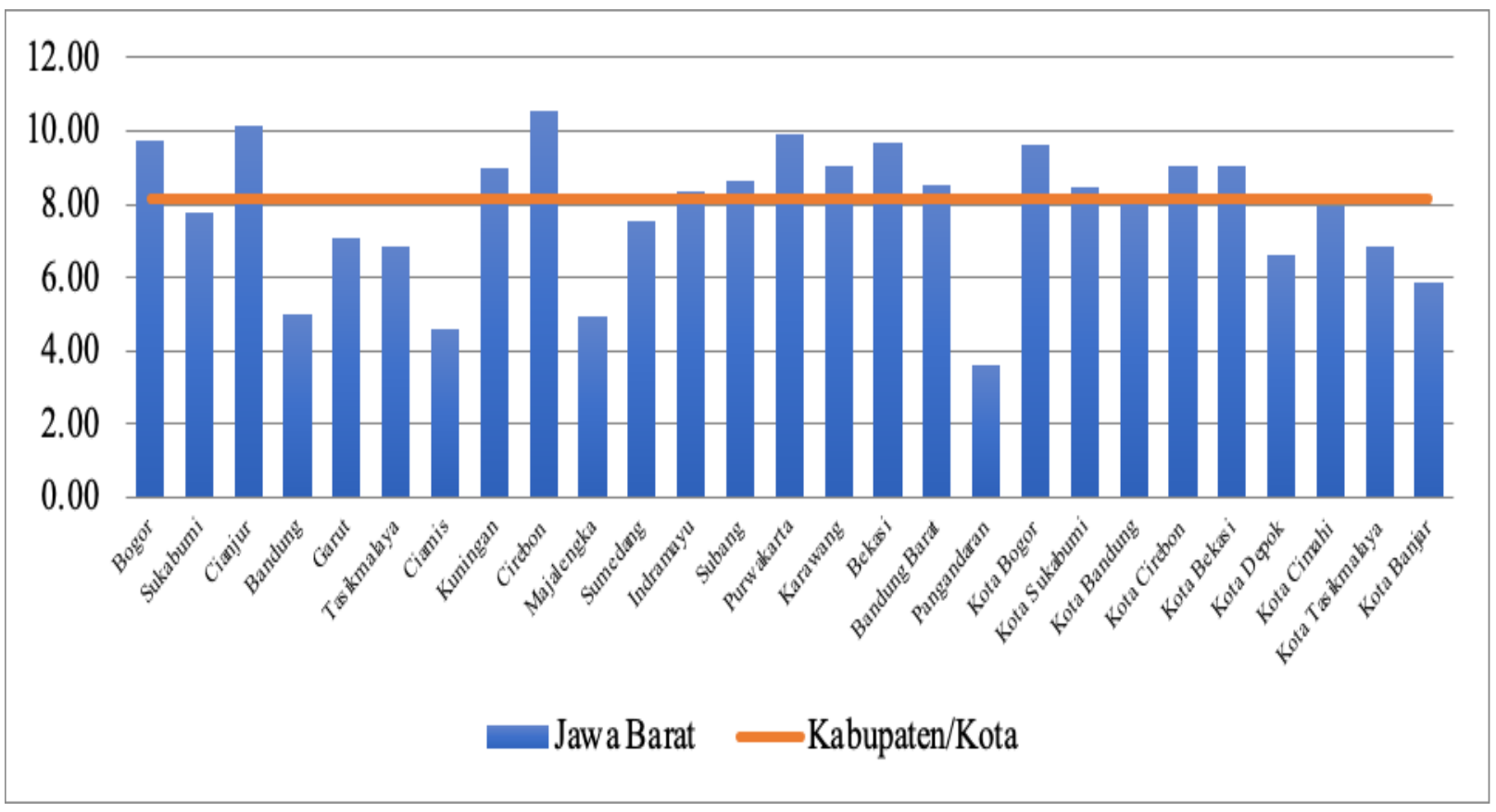

Sumber: BPS Jawa Barat (2018)

\section{Gambar 2.}

Tingkat Pengangguran Terbuka Kabupaten/Kota di Provinsi Jawa Barat Tahun 2018 (dalam persen)

Tingkat penganguran terbuka di Kabupaten/Kota Provinsi Jawa Barat dari tahun 2018. Beberapa daerah di Jawa Barat sudah melebihi angka pengangguran provinsi Jawa Barat, dimana tingkat pengangguran terbuka tertinggi yaitu kabupaten di Jawa Barat diantaranya Bogor, Cianjur, Kuningan, Cirebon, Indramayu, Subang, Purwakarta, Karawang, Bekasi dan Bandung Barat. Sedangkan pengangguran daerah kota tertingi di Jawa Barat terdapat di Bogor, Cirebon dan Bekasi.

Adanya pengangguran tersebut dapat disebabkan dengan ketidakseimbangan pekerjaan dan jumlah tenaga kerja, dimana persaingan ketat pada setiap lulusan menjadi salah satu penyebab ketidakseimbangan pekerjaan dengan tenaga kerja. Dalam hal ini, para lulusan akan semakin sulit untuk mendapatkan pekerjaan dikarenakan jumlah pekerjaan yang tersedia sangat sedikit. Adanya ledakan penduduk dapat sebagai pemicu peningkatan pengangguran dan menyebabkan para lulusan muda mengganggur. Para lulusan muda sudah mempersiapkan keahlian dan kualitas SDM.

Perkembangan Indeks Pembangunan Manusia (IPM) tahun 2018 di Kabupaten/Kota Jawa Barat berkategori tinggi dan sedang. Nilai IPM berkategori sedang terdapat di Kabupaten Bandung, Kabupaten Sumedang dan Kabupaten Bekasi. Selanjutnya, di daerah perkotaan memiliki nilai IPM yang sudah berkategori tinggi. Sementara itu, beberapa daerah seperti Kabupaten Bekasi, Kota Bogor, Kota Sukabumi, Kota Bekasi, Kota Depok dan Kota Cimahi sudah melebihi nilai IPM Provinsi Jawa Barat. Namun kualitas SDM yang di Kabupaten/Kota di Jawa Barat belum dapat menurunkan angka pengangguran di Jawa Barat yang cukup tinggi di Indonesia. 


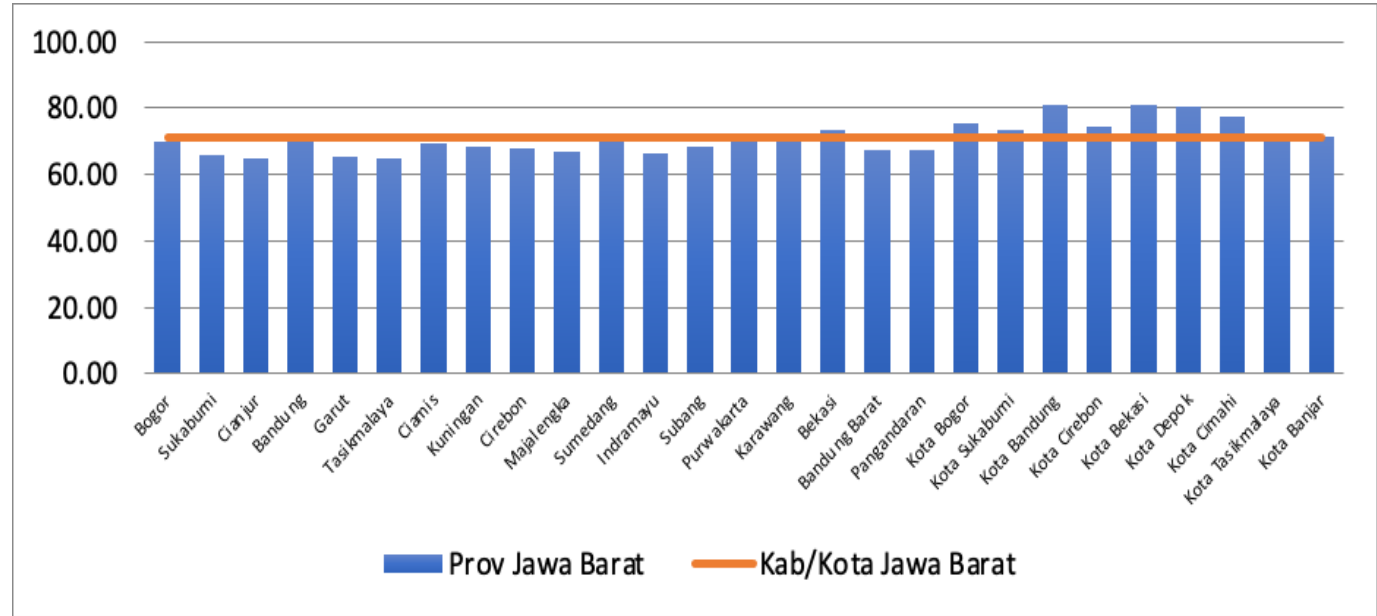

Sumber : BPS Jawa Barat (2018)

Gambar 3.

IPM Kabupaten/Kota di Provinsi Jawa Barat Tahun 2018 (indeks)

Pengangguran dapat timbul dari keterampilan dan pendidikan para pelamar, dimana latar belakang keterampilan dan pendidikan yang rendah akan menjadi sulit menjadi pekerja terampil. Banyaknya buruh kasar yang terjadi di Provinsi Jawa Barat akibat latar belakang pendidikan yang rendah. Adanya latar pendidikan rendah hanya menjadi buruh kasar yang mengakibatkan tidak adanya jiwa kewirausahaan. Kondisi kemampuan pendidikan dapat dilihat pada Gambar 4 berdasarkan ratarata lama sekolah 9 tahun berikut ini.

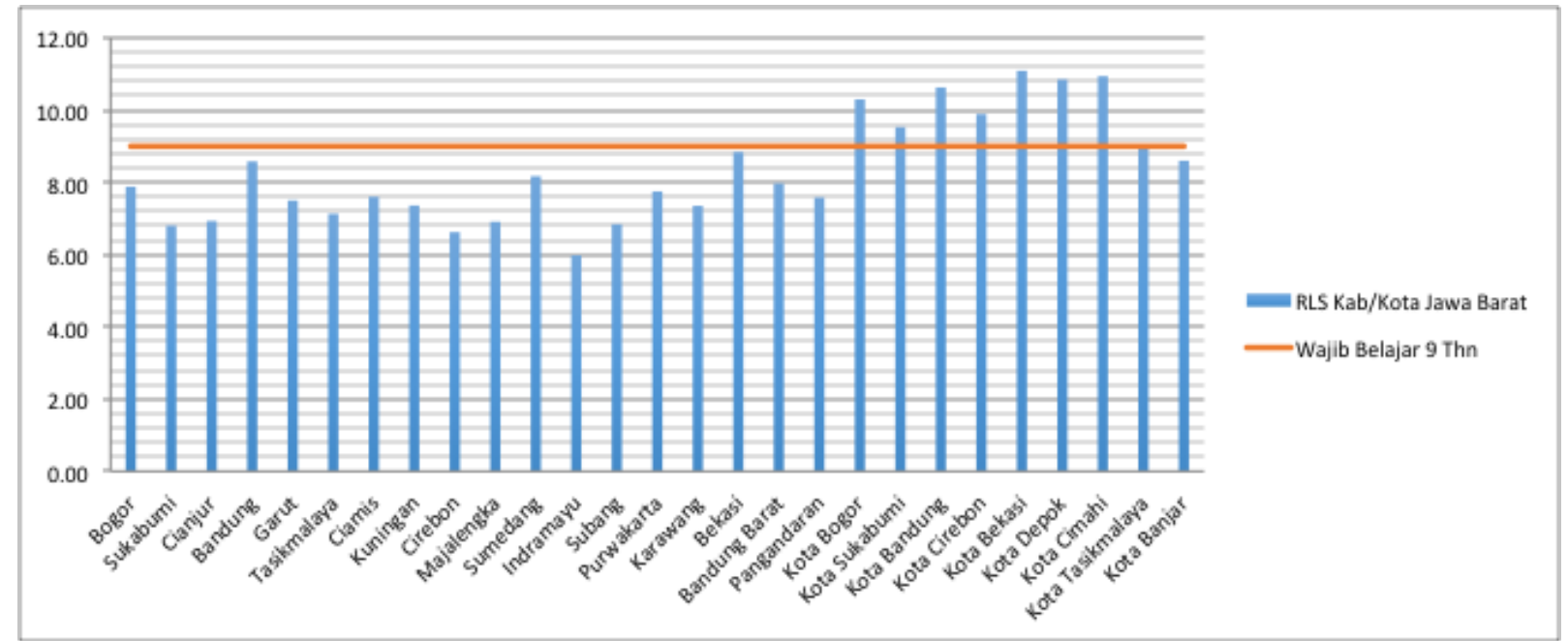

Sumber : BPS Jawa Barat (2018)

Gambar 4.

Persentase Capaian Pendidikan (Wajib Belajar 9 Tahun) Kabupaten/Kota di Jawa Barat Tahun 2018 (persen)

Pada Gambar 4 di atas menunjukkan masih banyak kabupaten/kota di Jawa Barat yang tidak memenuhi wajib belajar 9 melalui indikator Rata Lama Sekolah (RLS). Rata Lama Sekolah (RLS) memperlihatkan sejauhmana lama pendidikan yang ditempuh oleh individu dalam ruang lingkup wilayah. Hanya beberapa daerah saja yang sudah melebihi wajib belajar sembilan 9 (tahun) seperti di daerah perkotaan Jawa Barat. Pada umumnya masyarakat di Jawa Barat hanya dapat menjadi buruh yang tidak mengandalkan keahlian profesional. Hal ini akan menciptakan penurunan kualitas SDM yang dimana perusahaan karena membutuhkan tenaga profesional sehingga secara tidak 
langsung dapat menciptakan pengangguran di Jawa Barat. Pengangguran dapat berawal dari masyarakat yang berkategori orang miskin, padahal masalah kemiskinan akan ditangani secara serius oleh setiap negara maupun daerah. Kemiskinan terjadi akibat tingkat kemauan masyarakat untuk mendapatkan mata pencaharian yang rendah. Adanya faktor kemiskinan yang tinggi mengakibatkan kesempatan untuk mengeyam pendidikan dan memperoleh ketrampilan masih sangat minim dan berdampak terhadap peningkatan pengangguran.

Pada Gambar 5 dibawah ini memperlihatkan kondisi tingkat kemiskinan di daerah Jawa Barat berdasarkan persentase kemiskinan pada tahun 2018. Daerah yang melebihi kemiskinan provinsi Jawa Barat sebanyak 15 daerah yaitu Kab. Cianjur, Kab. Garut, Kab. Tasikmalaya, Kab. Kuningan, Kab. Cirebon, Kab. Indramayu, Kab. Majalengka, Kab. Sumedang, Kab. Subang, Kab. Purwakarta, Kab. Karawang, Kab. Bandung Barat, Kab. Pangandaran, Kota Cirebon dan Kota Tasikmalaya. Sementara itu, dari 15 daerah tersebut belum mampu mengurangi tingkat kemiskinan Provinsi Jawa Barat. Kemiskinan yang terjadi di Kabupaten/Kota Jawa Barat akan sulit mendapatkan pendidikan yang berjenjang serta mendapat ketrampilan. Kondisi ini akan mempersulit dalam penurunan pengangguran yang ada di daerah Jawa Barat.

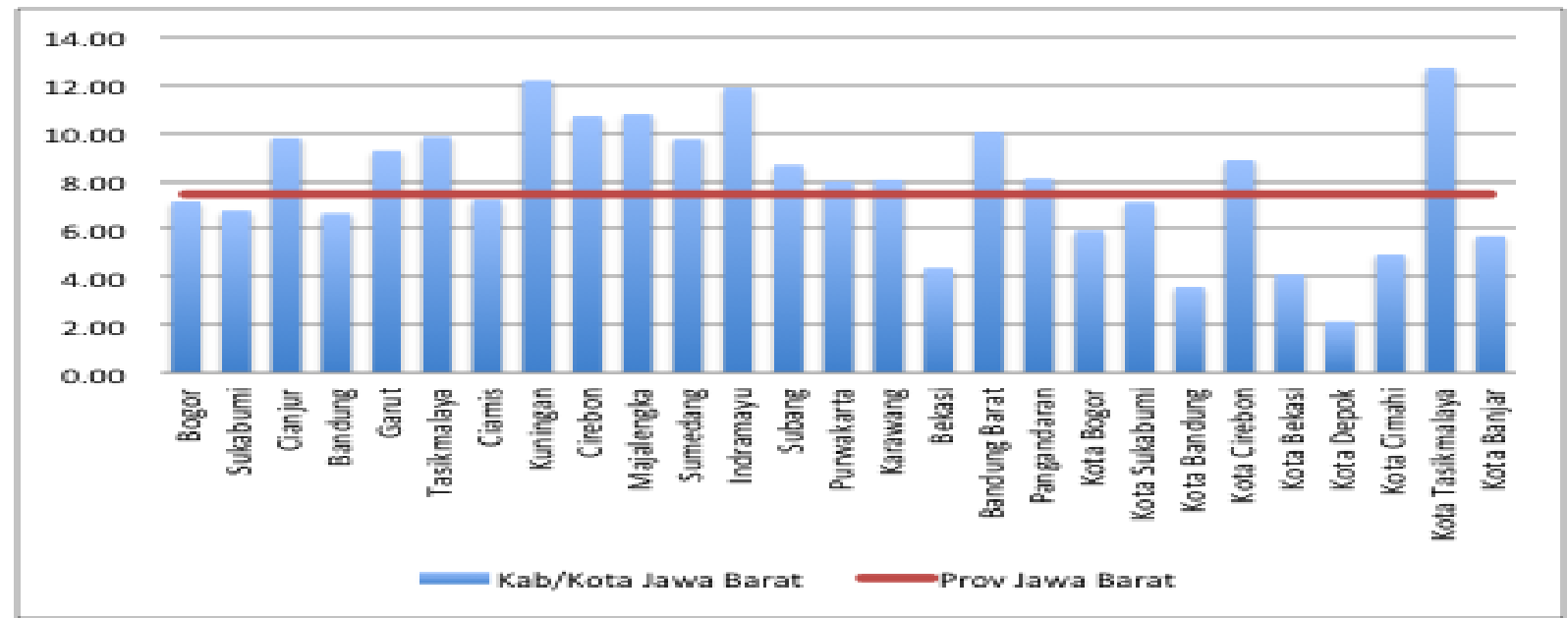

Sumber: BPS Jawa Barat (2018)

Gambar 5.

Tingkat Kemiskinan Kabupaten/Kota di Provinsi Jawa Barat Tahun 2018 (persen)

Permasalahan pengganguran di Jawa Barat masih banyak terjadi dari berbagai aspek, seperti adanya pemutusan hubungan kerja (PHK). Hal tersebut sering kali terjadi akibat kontrak kerja yang tidak dilanjutkan oleh perusahaan akibat pengurangan tenaga kerja. Selanjutnya, peningkatan upah minimum masih menjadi isu serius dan berkorelasi positif dengan PHK dan pengangguran. Adanya peningkatan upah minimum regional berakibat perusahaan secara umum beralih ke daerah lainnya yang berdampak terjadi PHK serta berdampak besar terhadap pengangguran. Pengangguran dapat disebabkan juga oleh minimnya pemerataan lowongan pekerjaan. Beberapa daerah yang kurang berkembang dan jauh dari lapangan pekerjaan akan mempersulit bagi masyarakat untuk mendapatkan pekerjaan yang diinginkan. Persaingan pasar global membuat perusahaan cenderung meningkatkan pekerja daerah asal dibandingkan dengan tenaga kerja di daerah asli. Oleh karena itu, peran kebijakan pemerintah dalam membuat peraturan diharapkan melindungi masyarakat dalam memperoleh pekerjaan dan beberapa faktor-faktor yang dapat meningkatkan pengangguran untuk segera dibenahi.

Penelitian mengenai determinan pengangguran yang terjadi di beberapa negara telah banyak dilakukan, misalnya Serneels, (2004) mempelajari sifat pengangguran kaum muda dan menganalisis insiden dan durasi pengangguran di Ethiopia menyimpulkan bahwa pengangguran kaum 
muda perkotaan untuk laki-laki tinggi pada 50\% pada tahun 1994 dan durasi rata-rata sekitar 4 tahun. Sementara itu, durasi lebih pendek terjadi pada individu yang bercita-cita untuk pekerjaan sektor publik dengan gaji tinggi dan memiliki ayah adalah pegawai negeri. (Broussar \& Tekleselassie, 2012) menggunakan data dari Gelombang Survei Sosial Ekonomi Perkotaan tahun 1994 dan 2000, mempelajari insiden pengangguran kaum muda di Ethiopia dengan fokus khusus pada pemuda perkotaan dan menemukan bahwa pengangguran kaum muda tinggi di lebih dari 50\% Muhammedhussen Batu, (2016) juga mempelajari determinan wirausaha di perkotaan Ethiopia dan menyimpulkan bahwa wirausaha lebih sedikit di antara kaum muda, berpendidikan dan mereka yang bermigrasi ke daerah perkotaan baru-baru ini. Pemberontakan baru-baru ini di Timur Tengah terutama di Mesir dan Tunisia yang menggulingkan rezim masing-masing dimotivasi oleh masalah sosial ekonomi utama seperti meningkatnya pengangguran (Behr \& Aaltola, 2011). Pendidikan tinggi yang di tamatkan oleh penduduk suatu wilayah di Indonesia memiliki dampak terbesar dalam penurunan tingkat pengangguran baik di suatu wilayah maupun di wilayah tetangganya (Oktafianto et al., 2019).

Aspek pendidikan melalui peningkatan kualitas SDM berperan penting, meskipun tidak secara langsung mempengaruhi penurunan pengangguran. Begitu juga dengan tingkat kemiskinan yang menjadi permaslahan serius yang perlu segera dibenahi agar tidak mendorong peningkatan pengganguran di Jawa Barat. Dengan demikian, penelitian ini akan mencoba menganalisia determinan pengangguran antar kabupaten/kota di Jawa Barat. Selain itu, penelitian ini akan melihat faktor-faktor mana saja yang dapat menurunkan tingkat pengangguran seperti perkembangan populasi, pertumbuhan ekonomi dan kemiskinan.

\section{METODE PENELITIAN}

Data penelitian yang digunakan bersumber dari Badan Pusat Statistik (BPS) Provinsi Jawa Barat. Model penelitian menggunakan pooled data, sebelum melakukan penelitian dimulai dengan pengujian chow test untuk menentukan apakah model menggunakan common effect atau fixed effect dan dilanjutkan dengan pengujian Hausmann test menentukan apakah model menggunakan fixed effect atau random effect. Kemudian penelitian ini melakukan pengujian statistik yaitu Uji t, Uji F dan uji asumsi klasik (multikolinearitas, autokorelasi dan heteroskedastisitas). Variabel tidak bebas yang digunakan penelitian ini adalah variabel pengangguran, sedangkan variabel penjelasan dalam penelitian yaitu variabel pendidikan yang diproksikan Rata Lama Sekolah (RLS). Variabel kontrol dalam penelitian ini adalah kemiskinan (POV), output perekonomian (PDRB) dan populasi (POP). Data yang digunakan adalah data sekunder secara panel data. Analisis yang digunakan bersifat data time series dari tahun 2011-2017 dan data cross section yang berjumlah 25 Kabupaten/Kota di Jawa Barat. Model yang digunakan pada penelitian ini mengacu penelitian sebelumnya adalah sebagai berikut (Sembiring \& Sasongko, 2019) :

$\operatorname{LnUNEMP}_{i t}=\alpha_{0}+\alpha_{1}$ RLS $_{i t}+\alpha_{2} \operatorname{LnPOV}_{\text {it }}+\alpha_{3} \mathrm{LNPDRB}_{\text {it }}+\alpha_{4} \mathrm{LnPOP}_{\text {it }}+\mathrm{e}_{\mathrm{it} .}$

\section{HASIL DAN PEMBAHASAN}

Penelitian ini diestimasi menggunakan regresi pooled data metode fixed effect. Metode fixed effect digunakan melalui hasil Uji Hausmann. Kemudian hasil regresi model pengangguran Jawa Barat bebas dari permasalah uji asumsi klasik, baik uji multikolinearitas, autokorelasi dan heterokedastisitas. Berdasarkan hasil estimasi menunjukan bahwa semua variabel tidak bebas seperti rata-rata lama seklah (RLS), kemiskinan (POV), output perekonomian (LNPDRB) dan populasi (LNPOP) mempengaruhi signifikan terhadap pengangguran di Jawa Barat. Nilai dari rata rata lama 
sekolah (RLS) sebesar -0.347, setiap kenaikan satu persen dari RLS akan menurunkan pengangguran sebesar $0.347 \%$ dengan asumsi cateris paribus. Hasil ini sejalan dengan penelitian sebelumnya, dimana selama ini, sembilan di Kabupaten/Kota Jawa Barat masih banyak yang belum memenuhi wajib belajar sembilan tahun (Wardhana et al., 2020).

Pekerja yang relatif lebih berpendidikan memiliki keunggulan komparatif dalam mendapatkan pekerjaan, karena pemberi kerja mempertahankan pekerja yang berpendidikan lebih tinggi, bahkan jika mereka berhenti atau kehilangan pekerjaan, pekerja yang lebih berpendidikan dipekerjakan kembali dalam waktu yang lebih lama, sedikit dibandingkan dengan pekerja yang berpendidikan relatif lebih rendah. Oleh karena itu, pengangguran umumnya lebih banyak terjadi di antara pekerja yang tidak berpendidikan atau relatif tidak berpendidikan menurut Aden dalam Hindun, (2019). Program pemerintah dalam pendidikan akan menghambat masyarakat dalam mencapai standar pendidikan untuk bekerja sehingga akan menimbulkan pengangguran. Program wajib belajar sembilan tahun yang tidak terpenuhi dapat berakibat tingginya pengangguran usia muda. Salah satu untuk memenuhi tenaga kerja yang berkualitas yaitu dengan memenuhi program pemerintah di bidang pendidikan seperti program wajib belajar. Pendidikan yang rendah di Jawa Barat akan membuat kesulitan bagi masyarakat untuk mendapatkan pekerja yang lebih professional. Masyarakat yang memiliki pendidikan tinggi akan memahami perubahan teknologi, tetapi dengan pendidikan yang rendah akan sulit memahami teknologi sehingga untuk meningkatkan kinerja menjadi rendah.

Kemiskinan mempengaruhi secara signifikan terhadap pengangguran. Nilai variabel kemiskinan sebesar 0.006, jadi setiap kenaikan 1 persen akan meningkatkan pengangguran sebesar $0.006 \%$ dengan asumsi cateris paribus. Masyarakat miskin dalam mengeyam pendidikan dan kesehatan sangat rendah yang hanya mengandalkan subsidi pemerintah sehingga kalah bersaing dalam mendapatkan pekerjaan akibat memiliki pendidikan yang rendah. Kesempatan mendapatkan pendidikan yang sangat rendah mengakibatkan masyarakat mengganggur. Penelitian Akhmad (2020) menunjukkan bahwa kemiskinan dan pengangguran memiliki efek kausalitas, diawali adanya shock kemiskinan yang berdampak terhadap peningkatan pengangguran dalam jangka pendek dan mengarah dalam suatu konvergensi. Pada umumnya pengangguran berdampak terhadap kemiskinan tetapi kasus di Indonesia dan khususnya di Jawa Barat tingginya angka kemiskinan, menjadi sulit untuk mendapatkan pendidikan dan kesehatan yang diinginkan dalam persyaratan pekerjaan. Masyarakat miskin umumnya berada di sektor pertanian, apabila sektor pertanian mengalami alih fungsi lahan mengakibatkan terjadi pengangguran di sektor pertanian. Jadi penganguran dapat berdampak dari rendahnya produktivitas sektor ekonomi atau adanya alih fungsi lahan.

Selanjutnya, output perekonomian berhubungan negatif dan signifikan terhadap pengangguran di Jawa Barat. Nilai koefisien dari output perekonomian sebesar 1.215, kenaikan output perekonomian sebesar 1\% akan menurunkan penggangguran sebesar $1.215 \%$ dengan asumsi cateris paribus. Banda et al (2016) dalam penelitiannya menjelaskan output perekonomian mempengaruhi negatif terhadap pengangguran. Perkembangan yang positif pada output akan memperbesar permintaan barang dan jasa sehingga pelaku usaha akan memproduksi barang dan jasa dengan cara meningkatkan input produksi seperti tenaga kerja. Penelitian Folawewo \& Adeboje (2014), hubungan negatif antara output ekonomi dan pengangguran sejalan dengan teori yang dikemukakan oleh Okun's law dan perlunya mengejar pertumbuhan ekonomi jangka panjang yang berkelanjutan dan mampu menghasilkan lapangan kerja yang cukup disuatu wilayah. Dengan mendorong daya beli maupun output akan merangsang penambahan tenaga kerja sehingga dapat menurunkan pengangguran. Nilai signfikansi dari output (PDRB) terhadap tingkat pengangguran dikarenakan adanya peningkatan PDRB Kabupaten/Kota di Jawa Barat yang diarahkan pada kegiatan sektor riil. Peningkatan kegiatan sektor riil akan memberikan kontribusi terhadap penyerapan tenaga kerja sehingga dapat menurunkan angka pengangguran di Jawa Barat. Beberapa sektor riil di Jawa Barat yang telah berkontribusi seperti 
sektor industry manufaktur, sektor jasa, sektor perdagangan, sektor pertanian, sektor akomodasi, sektor kontruksi dan sektor transportasi telah memberikan kontribusi besar terhadap output perekonomian Jawa Barat. Pada sektor tersebut mendominasi peningkatan PDRB dan menyerap tenaga kerja yang akan mengurangi angka pengangguran.

Tabel 1.

Hasil Regresi Pengangguran di Jawa Barat

\begin{tabular}{|c|c|c|c|}
\hline Variable & Coefficient & t-Statistic & Prob. \\
\hline $\mathrm{C}$ & 5.587 & 0.337 & 0.736 \\
\hline Rata-rata Lama Sekolah & -0.347 & -2.280 & 0.024 \\
\hline Tingkat Kemiskinan & 0.006 & 2.269 & 0.025 \\
\hline LN (PDRB) & -1.215 & -2.749 & 0.007 \\
\hline LN (Populasi) & 2.006 & 2.851 & 0.005 \\
\hline \multicolumn{4}{|l|}{ Fixed Effects (Cross) } \\
\hline KAB_BOGOR-C & -1.369 & KAB_PURWAKARTA-C & 1.051 \\
\hline KAB_SUKABUMI-C & -1.455 & KAB_KARAWANG-C & 0.527 \\
\hline KAB_CIANJUR-C & -1.557 & KAB_BEKASI-C & 0.728 \\
\hline KAB_BANDUNG-C & -1.202 & BANDUNG_BARAT $-\mathrm{C}$ & -0.686 \\
\hline KAB_GARUT-C & -1.834 & KOTA_BOGOR-C & 1.230 \\
\hline KAB_TASIKMALAYA-C & -1.598 & KOTA_SUKABUMI-C & 1.850 \\
\hline KAB_CIAMIS-C & -0.714 & KOTA_BANDUNG-C & 1.623 \\
\hline KAB_KUNINGAN-C & -0.804 & KOTA_CIREBON-C & 3.118 \\
\hline KAB_CIREBON-C & -1.400 & KOTA_BEKASI-C & 0.370 \\
\hline KAB_MAJALENGKA-C & -1.147 & KOTA_DEPOK-C & 0.497 \\
\hline KAB_SUMEDANG-C & -0.262 & KOTA_CIMAHI-C & 2.305 \\
\hline KAB_INDRAMAYU-C & -0.203 & KOTA_TASIKMALAYA-C & 0.463 \\
\hline KAB_SUBANG-C & -0.906 & KOTA_BANJAR一C & 1.377 \\
\hline Adjusted R-squared & 0.929 & & \\
\hline F-statistic & 82.634 & & \\
\hline Prob(F-statistic) & 0.000 & & \\
\hline Durbin-Watson stat & 1.871 & & \\
\hline
\end{tabular}

Sumber: Data diolah, 2020

Populasi mempengaruhi signifikan terhadap pengangguran. Nilai koefisien populasi sebesar 2.006, setiap peningkatan $1 \%$ dari populasi akan meningkatkan pengangguran sebesar 2,006 dengan asusmsi cateris paribus. Penelitian Bidemi \& F S A (2020), dalam penelitiannya menjelaskan bahwa populasi dan pengangguran memiliki hubungan yang positif. Hal ini merupakan bukti bahwa peningkatan populasi tidak akan mengurangi pengangguran. Oleh sebab itu, melibatkan populasi padat yang membuat mereka efisien dalam produktivitas jangka panjang akan memicu pertumbuhan ekonomi suatu wilayah dari berkurangnya pengangguran. Peningkatan jumlah penduduk, membuat pemerintah daerah di Jawa Barat untuk mempersiapkan lapangan kerja. Pertambahan jumlah penduduk akan memunculkan permasalahan secara dinamis terutama bagi daerah perkotaan. Pertambahan penduduk yang besar di perkotaan akan mempersempit lapangan kerja sehinga akan memacu peningkatan pengangguran. Provinsi Jawa Barat sebagai salah satu pusat pertumbuhan dan penduduk terbesar di Indonesia, mengakibatkan lapangan kerja menjadi sempit dan berdampak peningkatan angka pengangguran. Kesempatan kerja yang kurang akan memperbesar penggangguran. 
Pertambahan angkatan kerja yang didominasi oleh orang tidak bekerja akan menimbulkan permasalahan dalam menyediakan lapangan kerja. Peningkatan sektor riil menjadi salah satu solusi dalam meningkatkan lapangan pekerjaan. Pertambahan penduduk dan angkatan kerja yang tidak seimbang akan meningkatkan pengangguran. Pada penelitian Rabiu et al (2019), menjelaskan bahwa perlunya upaya pemerintah mendorong kebijakan dan arus industrialisasi. Perlunya penanaman modal asing untuk menyediakan peluang kerja bagi para penganggur. Pemerintah daerah Jawa Barat perlu memikirkan melalui program peningkatan mata pencaharian masyarakat melalui pemberian modal (kredit), pelatihan siap kerja dan peningkatan jumlah lulusan pendidikan tinggi.

\section{SIMPULAN DAN SARAN}

Pada penelitian ini determinan yang mempengaruhi pengangguran telah di analisis menggunakan panel data. Hasil penelitian ini menunjukan bahwa rata lama sekolah dan output ekonomi berhubungan negatif terhadap pengangguran, sedangkan kemiskinan dan populasi memiliki hubungan yang positif terhadap pengangguran. Aspek pendidikan memiliki pengaruh dalam menurunkan pengangguran, oleh sebab itu perlunya peningkatan target wajib belajar sembilan tahun sebagai upaya peningkatan kualitas SDM, terutama bagi daerah yang belum mencapai target. Hal ini dilakukan agar terbentuknya tenaga profesional yang dibutuhkan perusahaan ataupun yang mengembangkan kreatifitasnya untuk membuka lapangan pekerjaan baru. Kemudian perlunya mempercepat laju pertumbuhan ekonomi dengan meningkatkan output perekonomiannya. Selain dari output ekonomi, perlunya menjaga tingkat populasi agar keseimbangan di lapangan kerja terjaga dan angka pengangguran tidak terus meningkat.

Terakhir, kelemahan dari kajian ini adalah periode penelitian hanya terbatas pada periode 2012-2017. Dengan demikian, diharapkan penelitian selanjutnya dilakukan dengan periode waktu penelitian sampai dengan tahun 2020, terutama pada saat terjadi pandemi covid19. Hal tersebut perlu dilakukan, mengingat kondisi pendidikan sebelum dan sesudah adanya pamdemi covid19 akan berbeda.

\section{REFERENSI}

Akhmad, A. (2020). Hubungan Kausalitas Kemiskinan, Tingkat Pengangguran, Dan Pertumbuhan Ekonomi Di Provinsi Sulawesi Selatan. Jurnal Ekonomi Balance, 16(1), 13-23.

Badan Pusat Statistik. (2019). Indikator Angkatan Kerja.

Banda, H., Ngirande, H., \& Hogwe, F. (2016). The impact of economic growth on unemployment in South Africa: 1994-2012. Investment Management and Financial Innovations, 13(2), 246-255.

Behr, T., \& Aaltola, M. (2011). The Arab uprising. Causes, prospects and implications. Fiia Briefing Paper 76.

Bidemi, J., \& F, S. A. (2020). Dynamic Effect of Population Growth on Unemployment Rate in Nigeria. 8471, $103-113$

Broussar, N. H., \& Tekleselassie, T. G. (2012). Youth Unemployment, Ethiopia Country Study. International Growth Centre (IGC) Working Paper.

Folawewo, A. O., \& Adeboje, O. M. (2014). Macroeconomic Determinants of Labour Market Outcomes in Economic Community of West African States. The Indian Economic Journal, 62(1), 803-819. https://doi.org/10.1177/0019466220140107

Hindun. (2019). Impact of Education Level on Unemployment Rate in Indonesia. International Journal of Educational Research Review, 2(1) 321-324. https://doi.org/10.24331/ijere.573866

Mankiw, G. . (2006). Macroeconomics (9th Editio). Worth Publishers. 
Muhammedhussen Batu, M. (2016). Determinants of Youth Unemployment in Urban Areas of Ethiopia. International Journal of Scientific and Research Publications.

Oktafianto, E. K., Achsani, N. A., \& Irawan, T. (2019). The Determinant of Regional Unemployment in Indonesia: The Spatial Durbin Models. Signifikan: Jurnal Ilmu Ekonomi. https://doi.org/10.15408/sjie.v8i2.10124

Rabiu, M., Saidu, M. kabiru, Muktari, Y., \& Nafisa, M. (2019). Impact of Population Growth on Unemployment in Nigeria: Dynamic OLS Approach. Journal of Economics and Sustainable Development, 10(22), 79-89. https://doi.org/10.7176/jesd/10-22-09

Sembiring, V. B. P., \& Sasongko, G. (2019). Pengaruh Produk Domestik Regional Bruto, Inflasi, Upah Minimum, dan Jumlah Penduduk Terhadap Pengangguran di Indonesia Periode 2011 - 2017. International Journal of Social Science and Business. https://doi.org/10.23887/ijssb.v3i4.21505

Serneels, P. (2004). The Nature of Unemployment in Urban Ethiopia. In CSAE WPS.

Wardhana, A., Kharisma, B., \& Lingga, A. (2020). Pencapaian pendidikan dan kualitas sumber daya manusia antar kabupaten dan kota di jawa barat. FORUM EKONOMI, 22(2), 196-201. 